\title{
Máquina de Heron: desenvolvimento de um procedimento experimental para o ensino da termodinâmica a fim de entender as máquinas térmicas
}

\author{
Heron's Machine: development of an experimental procedure for \\ teaching thermodynamics in order to understand how thermal \\ machines
}

\author{
Wellington Gonçalves De Andrade [wellington.goncalves@aluno.ifsertao-pe.edu.br] \\ Thiago Alves de Sá Muniz Sampaio [thiago.muniz@ifsertao-pe.edu.br]
} Instituto Federal de Educação, Ciência e Tecnologia do Sertão Pernambucano (IF Sertão-PE) / Campus Salgueiro, BR 232, Km 504, sentido Recife, Zona Rural. CEP: 56000-000 | Salgueiro/PE Brasil.

\section{RESUMO}

O objetivo deste trabalho é apresentar a criação e/ou elaboração de um experimento simples e de baixo custo que contribua com o ensino-aprendizagem de conteúdos relacionados a termodinâmica, abordando principalmente o conceito das máquinas térmicas. A metodologia proposta pode fornecer à construção de conhecimentos a partir das ideias e interações prévias dos estudantes com a observação e discussão do experimento. Com isso, espera-se que o planejamento e execução de atividades práticas no ensino possa vir com o intuito de formar alunos como sujeitos críticos e interativos mediante aos assuntos científicos, além de tornar as aulas em sala mais dinâmicas e atrativas. Este experimento foi desenvolvido a fim de criar um dispositivo baseado no modelo de Heron de Alexandria, para demonstrar que as máquinas térmicas transformam a energia térmica em trabalho mecânico, no contexto da primeira lei da termodinâmica.

Palavras-Chave: Ensino de física, Experimento, Física experimental.

\begin{abstract}
The objective of this work is to present the creation and / or elaboration of a simple and low-cost experiment that contributes to the teaching-learning of contents related to Thermology, mainly addressing the concept of thermal machines. The proposed methodology can provide the construction of knowledge from the students' previous ideas and interactions with the observation of the experiment. With this, it is expected that the planning and execution of practical activities in teaching can come with the aim of training students as critical and interactive subjects through scientific subjects, in addition to making classroom classes more dynamic and attractive. This experiment was developed in order to create a device based on the Heron of Alexandria model, to demonstrate that thermal machines transform thermal energy into mechanical work, in the context of the first law of thermodynamics.
\end{abstract}

Keywords: Teaching Physics, Experiment, Experimental Physics.

\section{Introdução}

No contexto atual, o ensino de física tem enfrentado grandes problemas quanto à compreensão e interpretação dos conteúdos, como também a falta de custeio de equipamentos e de 
ANDRADE, Wellington; SAMPAIO, Thiago

Máquina de Heron: desenvolvimento de um procedimento experimental para o ensino da termodinâmica a fim de entender as máquinas térmicas

materiais didáticos para dar suporte ao ensino. Com isso, a aula torna-se repetitiva e cansativa, ocasionando a falta de interação e participação dos alunos.

Segundo JOÃO (2018):

É importante destacar, que apenas as aulas teóricas, por si só, não são mais capazes de despertar o interesse dos alunos. Um dos motivos da desmotivação é a concepção, por parte dos alunos, de que as aulas de física são apenas teóricas, sem qualquer vinculação com a realidade. Ademais, o aluno desmotivado tende a se afastar do conhecimento científico.

Neste contexto, cabe ao professor de Física identificar e sanar as dúvidas que permeiem a vida de seus alunos, proporcionando formas alternativas de aprendizagem eficazes, tanto quanto possível. Para isso, o uso de instrumentos pedagógicos, como a realização de experimentos, pode ser uma importante contribuição. (BENFíCA, 2020). Dessa forma, o aluno pode participar e construir o seu próprio conhecimento, desenvolvendo sua capacidade crítica; e o professor passa a ter um papel de mediador do processo de construção do conhecimento, assim permitindo aos alunos serem sujeitos na aprendizagem. Com esse ponto de vista, acreditamos que esse artigo pode trazer contribuições tanto para os alunos e professores do ensino médio, como também para a comunidade em geral.

De modo convergente a esse âmbito de preocupações, as atividades experimentais podem ser uma estratégia para o professor em suas aulas. Mais do que um fenômeno curioso para ser observado e admirado, o experimento constitui-se numa atividade pedagógica desenvolvida pelo aluno que inclui, intercaladamente, tarefas teóricas e experimentais, onde o fazer é importante, e o refletir para compreender é fundamental. (MORO, 2016).

Desta forma, este trabalho propõe a realização e discussão de uma atividade experimental simples e de baixo custo para o ensino de física. A proposta se baseia em uma fácil aquisição dos materiais e fácil montagem, permitindo que este tipo de atividade possa ser utilizada por professores ou estudantes da área de física, tanto em espaços formais quanto não formais, e em diferentes níveis de ensino.

A finalidade do presente artigo é propor um procedimento experimental para a montagem de um dispositivo que tem seu funcionamento similar à Máquina de Heron, para em seguida testar a teoria da primeira lei da termodinâmica, que diz que o calor pode ser utilizado para a realização de trabalho mecânico através dos conceitos físicos da termodinâmica. 0 artigo visa explicar a elaboração e execução de um experimento físico de baixo custo que simula os princípios térmicos e conceituais da máquina de Heron, podendo ser usado como recurso didático em sala de aula no conteúdo de termodinâmica.

\section{Fundamentação teórica}

\subsection{Máquinas térmicas e leis da termodinâmica}

Máquinas térmicas são máquinas capazes de realizar trabalho a partir da variação de temperatura entre uma fonte fria e uma fonte quente. A grande maioria dessas máquinas retira 
ANDRADE, Wellington; SAMPAIO, Thiago

Máquina de Heron: desenvolvimento de um procedimento experimental para o ensino da termodinâmica a fim de entender as máquinas térmicas

calor de uma fonte quente. Parte desse calor realiza trabalho e a outra parte é jogada para a fonte fria, definindo, dessa forma, a eficiência da máquina. Uma máquina térmica tem maior eficiência quando ela transforma mais calor em trabalho, portanto, rejeita menos calor para a fonte fria (SANTOS, 2016).

É interessante ressaltar o quanto as máquinas térmicas estão presentes no nosso dia a dia e que elas são usadas em meios de transporte e nas indústrias. Podemos citar alguns exemplos de máquinas térmicas, tais como os veículos automotores, as máquinas e turbinas a vapor, as geladeiras, os aparelhos de ar-condicionado, dentre outros.

De acordo com as leis da termodinâmica, as máquinas térmicas precisam receber certa quantidade de calor para ser convertida em um trabalho útil, pois mesmo que toda a energia fornecida ao sistema fosse conservada, apenas uma parte seria reaproveitada para a realização de trabalho, pois nenhuma máquina térmica é capaz de converter todo calor em trabalho.

A equação que descreve matematicamente a Primeira Lei da Termodinâmica é escrita como:

$$
\Delta U=Q-W
$$

Desta forma, seu fundamento é: A variação da energia interna de um sistema termodinâmico $\Delta U$ corresponde à diferença entre a quantidade de calor trocada com o ambiente $Q$ e a quantidade de trabalho realizado durante a transformação W (HELERBROCK, 2020).

A variação de energia interna $\Delta U$ refere-se à mudança de energia atribuída à energia cinética das partículas constituintes do sistema. Ela depende diretamente da temperatura do sistema, sendo proporcional a mesma. Caso não ocorra uma mudança de temperatura no sistema, sua energia interna também permanecerá inalterada $(\Delta U=0)$. Além disso, é importante dizer que, para as máquinas térmicas que operam em ciclos, a variação da energia interna, ao final de cada ciclo, deve ser nula, pois nesse ponto, a máquina volta a girar com a temperatura inicial (MOYSÉS, 2002, pág. 167).

As máquinas térmicas são dispositivos capazes de converter calor proveniente de uma fonte térmica em energia mecânica, sendo utilizadas principalmente como meios de transporte e nas indústrias. Podemos exemplificar as máquinas a vapor, que são máquinas que funcionam pela transformação de energia térmica em energia mecânica através da expansão do vapor de água. 0 inventor da primeira máquina a vapor que se tem notícia até hoje foi Heron de Alexandria, que fez contribuições significativas para o campo das ciências exatas e, acima de tudo, na geometria. Heron foi um matemático e mecânico grego, que viveu em Alexandria no Egito, entre os anos 10 D.C. e 70 D.C. (GABI, 2020).

Na área da Termodinâmica, Heron criou, por volta do século I D.C., o primeiro dispositivo/ máquina a vapor conhecida e documentada: Eolípila de Heron ou Máquina de Heron. A máquina consistia numa esfera metálica, pequena e oca com água montada sobre um suporte de cano ligado a uma bacia com água. Na esfera eram fixados dois canos em forma de L. Quando a água é aquecida, produz um vapor que escapava por esses canos em forma de L. Então, a esfera adquire um movimento giratório, como demonstra a ilustração na Figura 1. 
ANDRADE, Wellington; SAMPAIO, Thiago

Máquina de Heron: desenvolvimento de um procedimento experimental para o ensino da termodinâmica a fim de entender as máquinas térmicas

Figura 1- Ilustração da Eolípila de Heron ou Máquina Térmica de Heron.

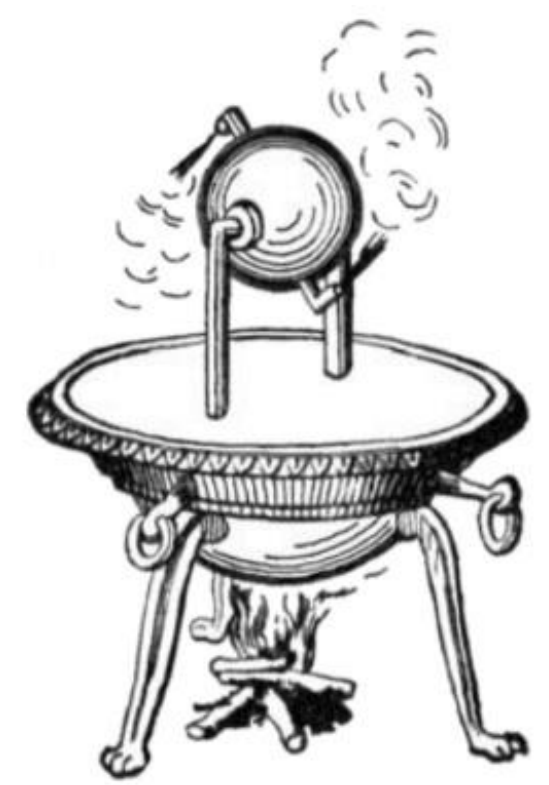

Fonte: "Aeolipile illustration" by The entry under Aeolipile in volume one of this work states "The cut is copied from Hero's "Spiritalia”, edited by Woodcroft, of London." - Knight's American Mechanical Dictionary, 1876.

Este dispositivo criado por Heron era uma máquina térmica: transforma calor em trabalho mecânico. Contudo, a invenção de Heron não foi utilizada para produzir grandes quantidades de energia mecânica. Foi apenas no século XVIII que foram construídas as primeiras máquinas capazes de realizar trabalhos industriais e automotivos.

\subsection{Torque e movimento circular}

O funcionamento da máquina de Heron acontece quando a água recebe energia térmica proveniente da fonte de calor, passando então para a forma de vapor, que sai de forma rápida. A saída do vapor de água devido à sua expansão exerce uma força de ação, enquanto a força de reação atua empurrando o cano no sentido contrário ao da ejeção de vapor, ocasionando desta forma um movimento circular no dispositivo, como podemos observar diante da Figura 2.

Figura 2- Movimento da máquina de Heron. 


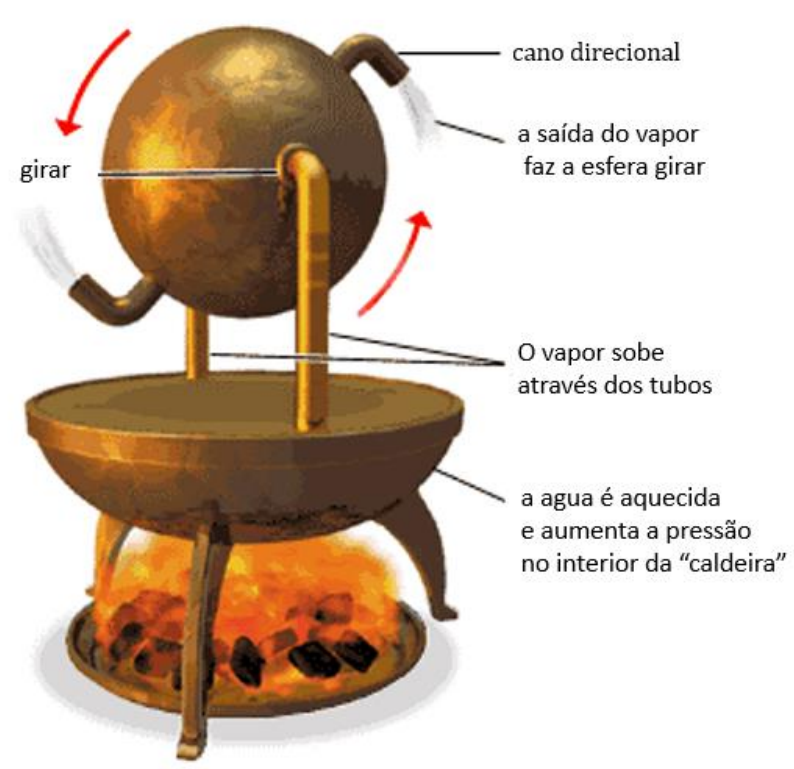

Fonte: In Encyclopædia Britannica. 2000.

Essa transmissão de rotação se deve predominantemente devido ao torque transmitido. Em outros termos, o torque consiste na ação de girar um corpo em torno do seu eixo de rotação por meio da aplicação de uma força (MOYSES, 2013). Podemos demonstrar esse conceito através da Figura 3, onde são mostrados os vetores atuantes na máquina para que o torque resulte em um movimento circular da máquina.

Figura 3- Vetores atuantes da máquina de Heron.

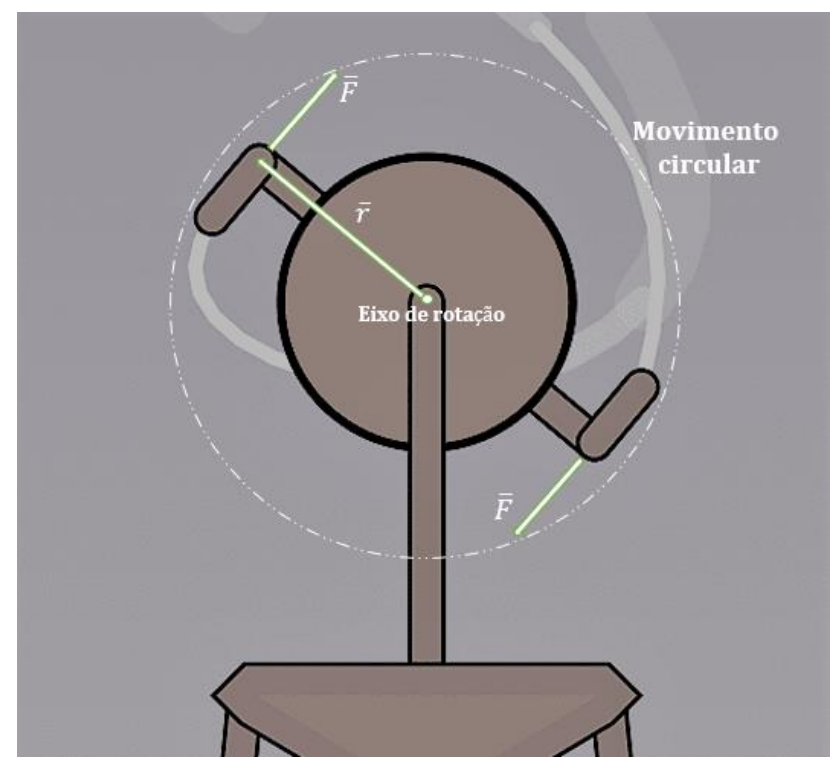

Fonte: o autor (2021).

Como o vetor torque é o resultado do produto vetorial entre o vetor do braço de alavanca (r) e o vetor força $(F)$, sua direção será sempre perpendicular ao plano formado por esses vetores, com o seu sentido dado pela regra da mão direita. O ângulo entre os vetores $r$ e $F$ é, portanto, fundamental, de modo que, para se obter uma otimização da transformação de energia térmica para energia mecânica, é essencial que os vetores sejam perpendiculares entre si no experimento.

Além disso, na Figura 3, percebe-se que vai existir a presença de dois torques atuantes na 
ANDRADE, Wellington; SAMPAIO, Thiago

Máquina de Heron: desenvolvimento de um procedimento experimental para o ensino da termodinâmica a fim de entender as máquinas térmicas

máquina, no caso, um torque resultante no sistema, que é determinado pela soma dos dois torques. Porém, se a soma desses torques for nula, esse sistema tenderá a permanecer em equilíbrio rotacional: parado ou em movimento circular uniforme, ou seja, girando com velocidade constante (na ausência de forças dissipativas).

\section{Materiais e métodos}

Foi montado um dispositivo que relaciona o conteúdo da termodinâmica mediante a construção conjunta de uma máquina térmica similar a Máquina de Heron. A montagem é bastante simples e o material é bem acessível. Para a montagem do dispositivo, são necessários os seguintes materiais: (a) frasco de vidro de esmalte $8 \mathrm{ml}$; (b) canudo de plástico; (c) massa Epóxi; (d) serra manual; (e) tesoura; (f) linha para costura; (g) palito de churrasco; (h) algodão (i) álcool e (j) caixa de fósforos. Como podemos ver na Figura 4.

Figura 4- Materiais necessários para montar o dispositivo.

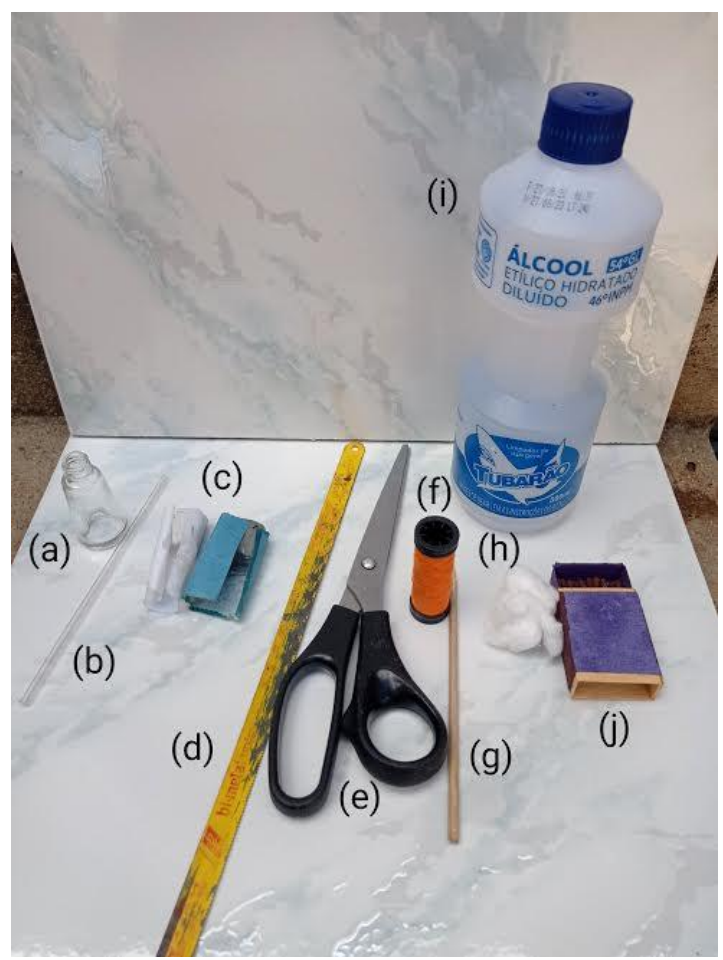

Fonte: o autor (2021).

Primeiro, foi feita a remoção da "boca" do frasco de esmalte com o auxílio de uma serra manual e adicionados água (4 ml). Em seguida, com o auxílio da tesoura, corta-se o canudo em duas partes $(6 \mathrm{~cm})$ de modo a encaixá-los dentro do frasco onde está contendo água. A posição dos canudos deve estar disposta horizontalmente e apontando em sentidos opostos um do outro, para que desta forma haja um torque resultante, fazendo o dispositivo girar. Usando a massa Epóxi, seguindo as instruções da embalagem, misturamos cada pedaço de massa até ficar homogênea e usamos para vedar os canudos dentro do frasco, fazendo com que a única saída de ar do frasco seja pelas bocas das partes do canudo. Por final, com tudo pronto, pendura-se o sistema com uma linha de costura amarrada a um palito de churrasco, para servir como sustento. 0 dispositivo deve ficar como mostra a Figura 5. 
Figura 5- Dispositivo que simula a máquina de Heron.

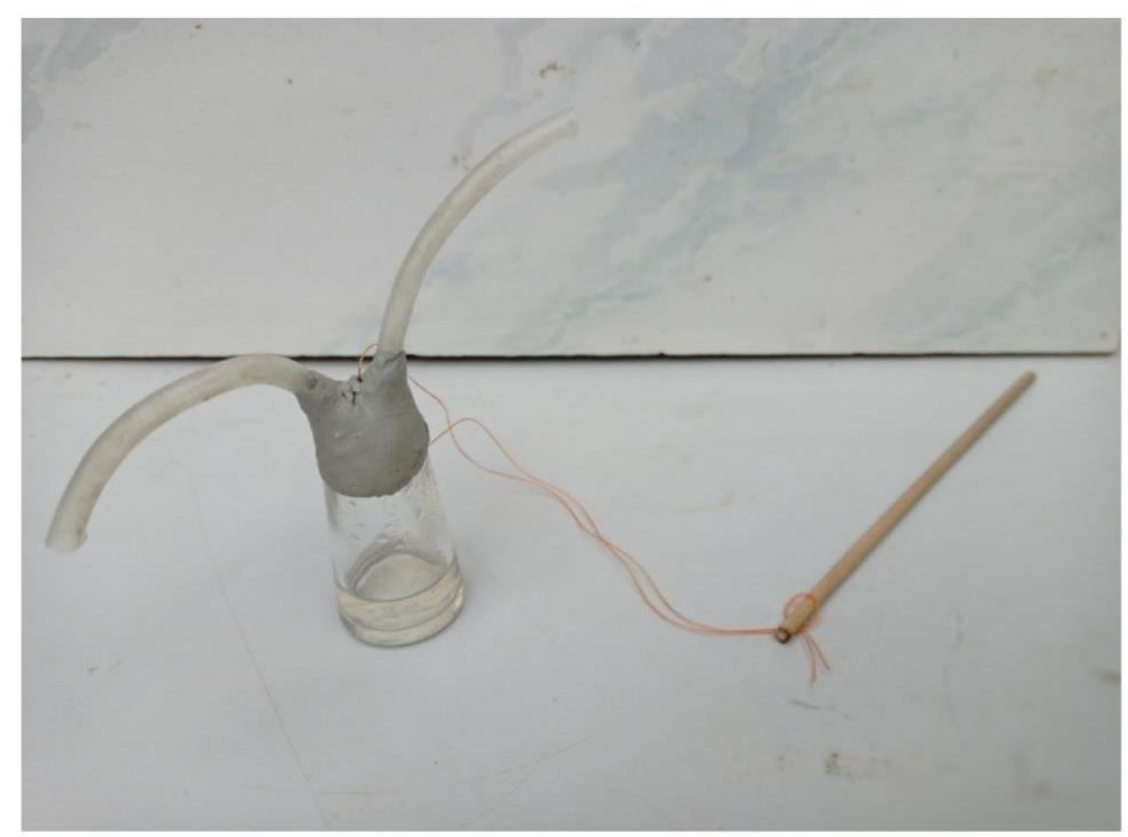

Fonte: o autor (2021).

Depois de pronto, para testar o dispositivo que simula a máquina de Heron, é necessário algum material inflamável para ceder calor ao sistema. No caso, foi usado o algodão que foi molhado com álcool e ascendido com a chama do palito de fósforo. Para questões de segurança no manuseio do algodão inflamável, coloca-o embaixo do frasco de esmalte com água e depois o ascende, ou pode usar uma pinça de sobrancelha para servir com um pegador a fim de proteger a mão. Quando a chama do algodão começa a esquentar o dispositivo, percebe-se que a água contida no mesmo começa a produzir vapor. Esse vapor de água passa pelos canudos de plásticos, fazendo com que o sistema gire, como é mostrado na Figura 6.

Figura 6- Máquina em funcionamento. 
ANDRADE, Wellington; SAMPAIO, Thiago

Máquina de Heron: desenvolvimento de um procedimento experimental para o ensino da termodinâmica a fim de entender as máquinas térmicas

Fonte: o autor (2021).

Após testar o experimento, é possível discutir os conceitos relacionados à primeira lei da termodinâmica e das máquinas térmicas, uma vez que o mesmo discute de forma clara a abordagem física da termodinâmica e do torque; e destaca como as máquinas térmicas têm papel muito importante no desenvolvimento tecnológico e industrial.

\section{Resultados e discussões}

Nessa experiência pode-se notar que quando o vapor de água escapava pelos canudos, o dispositivo girava lentamente. Esse fato pode trazer questionamentos à tona para os estudantes, pois talvez não sejam todos que entendem o processo experimental. Para que esse conflito seja esclarecido é necessário que o professor resuma os assuntos já dados: A teoria da termodinâmica explica a troca de calor entre sistemas e o trabalho realizado por um processo físico, uma vez que, o exemplo dado diz que uma máquina térmica se aplica atualmente em várias situações do nosso cotidiano.

No experimento, pode ser explicado que, quando aquecemos o frasco, a água que está contida nela se transforma em vapor, e com isso seu volume aumenta. Neste processo de expansão, a pressão interna aumenta e o vapor é forçado a sair pelos tubos em alta velocidade. Desta forma o frasco realiza um trabalho mecânico ao girar. Pode-se perceber também que, no momento em que o vapor de água se expande, este tende a aumentar a rotação do dispositivo, com isto, o torque vai ficar maior e consequentemente realizará um trabalho para que o mesmo tenha um movimento circular.

O dispositivo gira inicialmente devido ao torque resultante nos dois canudos. Se considerarmos os dois canudos, existirá uma soma dos dois torques presentes nos dois lados do dispositivo, que fará o sistema girar. Pelo teste do experimento realizado pelo autor, pelo que mostra a figura 6 , pode-se perceber que o lado direito tem um torque maior do que o esquerdo, visto que ele está mais na horizontal. Portanto, o dispositivo girará no sentido horário. Caso se posicione os canudos de forma que não haja torque resultante, ou seja, se os canudos estiverem no sentido da vertical, por exemplo, o dispositivo não apresenta movimento rotacional.

Esse dispositivo pode ser explicado pela a Primeira Lei da Termodinâmica, porque parte da energia que o frasco recebe na forma de calor através da chama é transformada em trabalho útil quando o vapor sai pelos canudos, ou seja, uma parte do calor se transforma em trabalho para movimentar os mesmos, e consequentemente, ocorre a diminuição da pressão e da temperatura do vapor. Com isso, o dispositivo volta a girar com a temperatura inicial e o ciclo se repete enquanto ele permanecer sobre a chama.

Fisicamente dizendo, quando a chama do algodão entrou em contato com o frasco de vidro, que continha água, esta água esquentou (recebeu um calor $Q$ ) que fez aumentar a energia interna $U$ do sistema (energia de translação das partículas de água). A água transformou-se então em vapor, que aumentou a pressão interna do frasco, procurando um caminho de saída (pelos canudos). Ao sair com velocidade rápida, realizou um trabalho (provocando o giro do sistema).

A variação da energia interna de um sistema $(\Delta U)$ pode ser positiva $(\Delta U>0)$ ou negativa $(\Delta U$ $<0$ ), ou seja, pode-se fornecer energia térmica para um sistema e aumentar sua energia interna 
ANDRADE, Wellington; SAMPAIO, Thiago

Máquina de Heron: desenvolvimento de um procedimento experimental para o ensino da termodinâmica a fim de entender as máquinas térmicas

(que é o que foi feito para a Máquina de Heron), mas pode-se também retirar energia térmica de um sistema (resfriá-lo) e diminuir assim sua energia interna, que é o que vai acontecer quando se apagar a chama debaixo do frasco.

\section{Considerações finais}

Uma das dificuldades que os alunos apresentam nas aulas de Física está relacionada com a compreensão dos conteúdos apresentados pelo professor. Isso acaba deixando os alunos bastante desinteressados pelas aulas. Por isso, se faz necessária a realização de aulas experimentais, a fim de despertar o interesse e aguçar a curiosidade dos alunos, se tornando então algo de grande importância no desenvolvimento cognitivo do aluno. Além disso, tais atividades possibilitam aos estudantes uma visualização do contexto de forma clara e objetiva, tornando uma aula mais atrativa, incentivando a interação dos alunos na construção de conhecimento e contribuindo para o melhoramento do ensino-aprendizagem.

Este trabalho tratou da temática do ensino da Termodinâmica para estudantes do ensino básico ou estudantes de formação acadêmica, no qual a essência das estratégias pedagógicas centraliza-se no desenvolvimento de um experimento de baixo custo, que proporciona a compreensão dos alunos acerca da dimensão da termodinâmica, mediante a integração dos conteúdos e a possibilidade de o estudante participar ativamente da investigação a respeito das máquinas térmicas, favorecendo, portanto, a aprendizagem.

\section{Referências}

ARAÚJO, Mauro Sérgio Teixeira de; ABIB, Maria Lúcia Vital dos Santos. Atividades experimentais no ensino de física: diferentes enfoques, diferentes finalidades. Revista Brasileira de ensino de física, v. 25, n. 2, p. 176-194, 2003.

BENFÍCA, Kátia Ferreira Guimarães; PRATES, Kimelly Hanna Guimarães. As contribuições do uso de experimentos no ensino - aprendizado da física. Brazilian Journal of Development, v. 6, n. 6, p. 33686-33703, 2020.

CONHECIMENTOCIENTIFICO. Heron de Alexandria, quem foi? História, principais invenções e legado.

Disponível em: https://conhecimentocientifico.r7.com/author/gabinoronha/, Acesso em $02 / 03 / 2021$

DA SILVA, JOÃO BATISTA; SALES, GILVANDENYS LEITE. Atividade experimental de baixo custo: o contributo do ludião e suas implicações para o ensino de Física. Revista do Professor de Física• Bras ília, v. 2, n. 2, 2018.

GRASSELLI, Erasmo Carlos. Uma abordagem das máquinas térmicas no ensino da termodinâmica sob a ótica da aprendizagem significativa. 2018. 167 f. Dissertação (Mestrado em Ensino de Física). Universidade Tecnológica Federal do Paraná, Medianeira, 2018. Disponível em: https://repositorio.utfpr.edu.br/jspui/handle/1/4446, Acesso em 20/02/2021. 
ANDRADE, Wellington; SAMPAIO, Thiago

Máquina de Heron: desenvolvimento de um procedimento experimental para o ensino da termodinâmica a fim de entender as máquinas térmicas

HELERBROCK, Rafael. "Primeira Lei da Termodinâmica"; Brasil Escola. Disponível em: https://brasilescola.uol.com.br/fisica/primeira-lei-da-termodinamica.htm. Acesso em 28 de junho de 2021.

MORO, Fernanda Teresa. Atividades experimentais e simulações computacionais: integração para a construção de conceitos de transferência de energia térmica no ensino médio. 2016. Dissertação de Mestrado.

NUSSENZVEIG, H. M. Curso de Física Básica 1: mecânica / H. Moysés Nussenzveig. - 5. ed. - São Paulo: Blucher, 2013.

NUSSENZVEIG, H. M. Curso de Física Básica 2: Fluidos, Oscilações e Ondas, Calor- $4^{\mathrm{a}}$ edição rev. São Paulo: Editora Edgard Blücher, 2002.

PARANÁ. Secretaria de Estado da Educação. Superintendência de Educação. Os Desafios da Escola Pú blica Paranaense na Perspectiva do Professor PDE, 2014. Curitiba: SEED/PR., 2016. V.1. (Cadernos PDE). Disponível em: Acesso em: 20/02/2021. ISBN 978-85-8015-080-3.

PORTAL DO PROFESSOR. Primeira Lei da Termodinâmica. Disponível em: http://portaldoprofessor.mec.gov.br/fichaTecnicaAula.html?aula=14397, Acesso em 02/03/2021. SANTOS, Marco Aurélio da Silva, Mundo Educação, Maquinas Térmicas, 2016. Disponível https://mundoeducacao.uol.com.br/fisica/maquinas-termicas.htm > acessado em 28/03/2021

SOLANGE, S. C.; RINALDI, C (2018). A atividade experimental no ensino de ciências naturais: contribuições e contrapontos. Experiências em Ensino de Ciências v.13, n.1, p. 306-320.

THOMAZ, M. F. (2000). "A experimentação e a formação de professores: uma reflexão". Cad. Cat. Ens. Fís., 17 (3): 360-369. 